\title{
IMPACTOS AMBIENTAIS DOS RESÍDUOS GERADOS NA PESCA ARTESANAL DE MOLUSCOS BIVALVE NO DISTRITO DE PATANÉ/AREZ-RN
}

\author{
G. F. LIMA e R. L. LOPES* \\ Instituto Federal de Educação, Ciência e Tecnologia do Rio Grande do Norte \\ regia.lopes@ifrn.edu.br ${ }^{*}$
}

Artigo submetido em novembro/2015 e aceito em abril/2016

DOI: $10.15628 /$ holos.2016.3668

\section{RESUMO}

A pesca artesanal apresenta importância econômica e social para comunidades do litoral brasileiro. O objetivo do presente estudo é diagnosticar a problemática do descarte inadequado do resíduo da pesca de moluscos na comunidade de Patané, Distrito de Arez/RN. O estudo foi realizado por pesquisa documental e de campo, com visitas na comunidade e entrevistas com pescadores $e$ representantes do órgão municipal. A comunidade é composta por 1.575 moradores que tem como atividade principal a pesca artesanal. Foram identificados cerca de 60 pescadores que realizam exclusivamente a pesca do molusco e tem essa atividade como a única fonte de renda. O principal impacto ambiental nessa atividade, constitui-se no descarte das conchas no próprio local de desembarque ou em quintais e terrenos baldios. Verificou-se que os principais fatores que contribuem para a atual situação de
\end{abstract}

acúmulo de resíduos da pesca em locais públicos e privados são: ausência de gestão da atividade por falta de capacitação dos pescadores, precariedade nas estruturas físicas de beneficiamento, ausência de estudos sobre alternativas locais para a reutilização das conchas em outros processos produtivos, e estrutura deficiente do órgão ambiental local para solução do problema. Acrescentem-se ainda os problemas sanitários causados na comunidade associados ao descarte em quintais e nos logradouros públicos, além da degradação do meio ambiente, principalmente nas áreas próximas a lagoa de Guaraíras. Dessa forma se faz necessário estudos de alternativas para solucionar de forma economicamente viável e ambientalmente sustentável o problema, tendo em vista a importância econômica e social da pesca artesanal desse molusco para a comunidade.

\section{ENVIRONMENTAL IMPACTS OF WASTE GENERATED IN BIVALVE MOLLUSCS OF HOMEMADE FISHING IN DISTRICT PATANE/AREZ-RN}

\begin{abstract}
Artisanal fishing has economic and social importance for the Brazilian coast communities. The aim of this study is to diagnose the problem of improper disposal of waste mollusk fishing (shells) in the community of Patané District Arez / RN. The study was conducted by documentary and field research, visits to community and interviews with fishermen and representatives of the municipal government. There are 1,575 residents in district that are primarily engaged in small-scale fishing and identified about 60 fishermen who exclusively perform fishing and has this activity like the only source of income. The main environmental impact is the disposal of shells landing in the site or in backyards and vacant lots. It was found that the main factors contributing to the current situation of fishery waste accumulation in
\end{abstract}

public and private places are: lack of management activity by lack of training of fishermen, precariousness in the physical structures of processing, absence of studies on alternative and promoting the re-use of the shells in other production processes, and poor structure of the local environmental agency for troubleshooting. In addition, there caused health problems in the community associated with the disposal in backyards and in public places, as well as environmental degradation, especially in the areas near Guaraíras lagoon. Thus it is necessary to study alternatives to solve an economically viable and environmentally sustainable the problem, given the economic and social importance of artisanal fisheries of this shellfish to the community 


\section{INTRODUÇÃO}

A pesca de moluscos no litoral brasileiro é uma atividade bastante difundida que se destaca com grande importância econômica, histórica, social e cultural, mas ao mesmo tempo tem causado bastante impacto ambiental nos manguezais. Segundo Pereira Filho e Alves (1999) o manguezal desempenha diversas funções naturais de grande importância ecológica e econômica, tais como: Proteção da linha de costa, retenção de sedimentos carreados pelos rios, ação depuradora, área de concentração de nutrientes, renovação da biomassa costeira e áreas de alimentação/abrigo.

No Rio Grande do Norte, muitas comunidades litorâneas praticam a pesca de moluscos em manguezais, tais como as localizadas nos municípios de Galinhos, Grossos, Macau (na chamada Costa Branca) e nos municípios de Arez, Georgino Avelino e Tibau do Sul localizados no litoral sul.

O molusco Anomalocardia brasiliana está presente em toda a costa brasileira e recebe diversos nomes tais como berbigão em Santa Catarina, vôngole em São Paulo, marisco na Paraíba, marisco pedra em Pernambuco, chumbinho na Bahia, búzio e lilio no Rio Grande do Norte. Segundo Silva (2007), o estado de Santa Catarina destaca-se no Brasil como o segundo maior produtor de moluscos bivalves da América Latina.

A captura do molusco A. brasiliana no litoral sul do estado do RN é uma atividade realizada de forma artesanal, cuja prática envolve diversas famílias que dependem financeiramente dessa atividade. Segundo Nishida (2000) para as comunidades ribeirinhas que vivem próximas aos manguezais, os moluscos representam um grupo de maior relevância econômica. Neste sentido a captura desse molusco se apresenta como uma alternativa para a oferta de alimentos e geração de renda nas comunidades locais envolvidas.

Em Arez/RN, no distrito de Patané, o resíduo gerado no beneficiamento deste molusco vem provocando um grande problema ambiental, pois o descarte se dá logo após o desembarque dos moluscos capturados, no próprio local de beneficiamento, nas margens do manguezal, ou nas suas proximidades e até em quintais e logradouros públicos das residências onde eles são beneficiados. Segundo Lima et al. (2007) quando o beneficiamento é realizado em locais próximos a extração, as conchas são deixadas no local em montanhas que se sobrepõem, causando consequentemente impacto ao meio ambiente.

Em vários países banhados pelo litoral já existem diversos projetos com alternativas para reutilização dos resíduos gerados na pesca desses moluscos e mariscos, porém ainda persiste problemas ambientais causados pelo descarte inadequado em muitas cidades do litoral brasileiro.

Este trabalho tem o objetivo de diagnosticar a problemática do descarte dos resíduos gerado no beneficiamento do molusco A. brasiliana na comunidade de Patané distrito de Arez/RN, e, sobretudo os possíveis impactos ambientais decorrentes dessa atividade, assim como as ações dos órgãos ambientais frente à essa problemática.

\section{METODOLOGIA}

\section{1 Área de estudo.}

O município de Arez localiza-se na microrregião do litoral sul do estado do Rio Grande do Norte, tendo sua área territorial de $113 \mathrm{~km}^{2}$. Sua sede é localizada nas coordenadas geográficas: 
60 11'40" sul e 35 09'37' oeste, com população de 13.166 habitantes, e Índice de Desenvolvimento Humano (IDH) de 0,606 de acordo com o IBGE (2010).

A localidade em estudo se encontra na Área de Proteção Ambiental (APA) Bonfim/Guaraíra, cuja extensão é de 42.000 ha, abrangendo os municípios de Arez, Nísia Floresta, Senador Georgino Avelino, São José de Mipibu, Goianinha e Tibau do Sul IDEMA (2014). A APA foi criada através do decreto estadual $\mathrm{n}$ - 14.369 de 22.03.1999, tendo como principal finalidade ordenar o uso, proteger e preservar os ecossistemas dunar, a Mata Atlântica, o manguezal, lagoas, rios e demais recursos hídricos, as espécies animais e vegetais inseridos na área em contexto (IDEMA, 2014), A figura 1 mostra a localização da área de estudo.

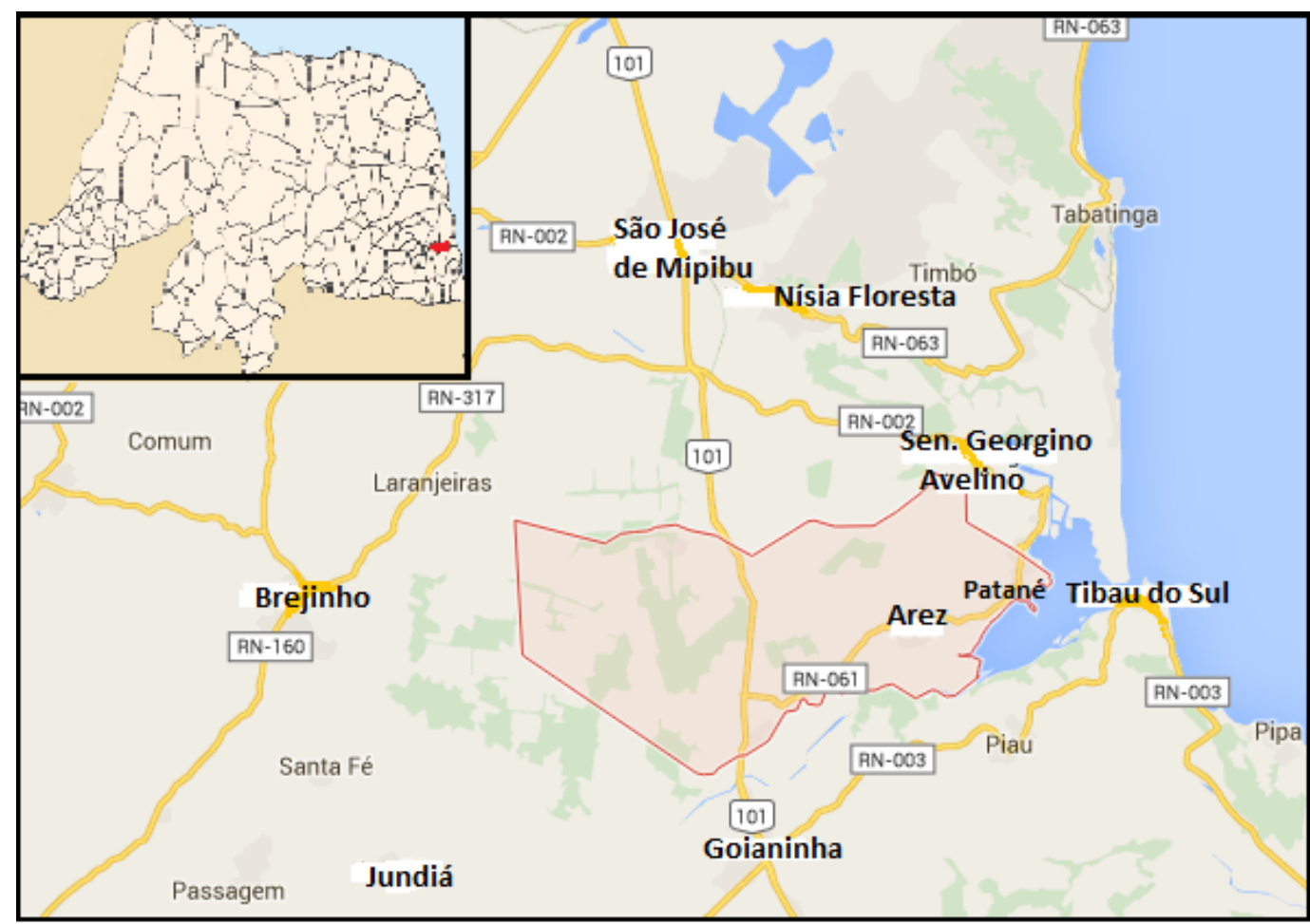

Figura 1: Localização da Área de estudo

Fonte: Os autores (2015)

\subsection{Procedimentos metodológicos}

Este trabalho se caracteriza, segundo Gil (2008) como uma pesquisa exploratória, que envolveu levantamento bibliográfico diretamente relacionado ao objeto de estudo e entrevistas informais acerca do processo produtivo. O estudo de campo ocorreu nos meses de maio a julho de 2015, na comunidade de Patané distrito de Arez/RN. O referido distrito tem uma população de 1.575 habitantes, com uma estimativa de 60 pescadores que sobrevivem da captura do molusco Iilio (A. brasiliana). Dentre esses cerca de 45 pescadores foram entrevistados sendo aplicado um questionário contendo questões que explorava as variáveis como: idade, sexo, moradia, fonte de renda, produção extraída, destino do lilio beneficiado/comercializado e destino dos resíduos gerados.

Foram realizadas quatro visitas aos locais para o aprofundamento da realidade especifica da geração de resíduos e impactos dessa geração no meio no meio ambiente e na comunidade. Por meio de registro fotográfico e entrevistas semiestruturadas com os pescadores e os 
representantes de órgãos ambientais se avaliou os impactos ambientais e sociais relacionados com essa atividade.

\section{RESULTADOS E DISCUSSÃO}

\subsection{Geração do resíduo a partir do beneficiamento do lilio (A. brasiliana)}

Durante as visitas de campo se verificou que os resíduos gerados a partir da extração do molusco lilio (A. brasiliana), representam um grande problema ambiental, pois após o beneficiamento do molusco os pescadores eliminam as conchas no próprio local, às margens do manguezal, sendo aproveitada somente a carne que é comercializada, gerando montanhas enormes de resíduos. Segundo Dias et al. (2007) para cada quilo de carne obtido do molusco são gerados $16 \mathrm{~kg}$ de conchas. Rego Neto e Batista (2014) estimam que as conchas representam de $75 \%$ a $90 \%$ do peso total, gerando, portanto, ao final do processamento, um volume bastante representativo. De acordo com dados da produção dos pescadores entrevistados estima-se uma geração mensal de cerca de 4 toneladas de conchas que são descartadas a céu aberto para uma produção média comercializada de $400 \mathrm{~kg}$ de lilio.

As estruturas para beneficiamento do lilio são geralmente muito rudimentares e se localizam às margens da lagoa de Guaraíras (no mangue), local de extração do molusco, tendo em vista a dificuldade para o transporte da produção dos locais de desembarque até as residências devido a inexistência de acessos para veículos. Assim sendo, a dificuldade ou ausência de logística de transporte do molusco até um local adequado, influencia diretamente na decisão dos pescadores em realizar o processamento próximo aos portos onde são descarregados a produção que é extraída diretamente do mangue.

A realização do beneficiamento no próprio local, embora facilite o transporte da produção apenas da carne para as residências e pontos de comercialização do produto, promove o descarte a céu aberto dos resíduos da produção gerando montanhas conchas que se sobrepõem, que causam impacto visual e no solo, como é mencionado também por Lima et al. (2007).

Durante o levantamento em campo foi observado que cerca de $9 \%$ dos entrevistados realizam o beneficiamento em seus domicílios. O motivo alegado para realizar o beneficiamento em casa, mesmo dispendendo um grande esforço físico para o transporte do material, é conciliar com as atividades domésticas e um maior conforto nessa tarefa.

\subsection{Impacto social a partir da extração do lilio}

A pesca do lilio é de grande importância para a população de Patané, tendo em vista que além dos pescadores e famílias que sobrevivem financeiramente dessa atividade, existem outros atores envolvidos na comercialização desse produto, tornando-se uma importante fonte de renda na comunidade. No processo de comercialização do produto, também está incluído donos de bares, além dos atravessadores que vem à comunidade só para comprar a produção dos pescadores para revenderem a preços superiores na capital e até em outros estados.

Nessa atividade predomina a participação do sexo masculino como agente do processo, desde a captura até o beneficiamento. Dentre os 45 pescadores pesquisados, 27 (60\%) são do sexo 
masculino e 18 (40\%) são do sexo feminino, que de uma maneira geral utiliza o molusco para alimentação da família.

A falta de emprego no município tem contribuído para a busca de outra fonte de geração de renda, como pode ser constatado durante as entrevistas onde um pescador declarou que é pedreiro de oficio e quando não há trabalho na região, vai para atividade da pesca juntamente com a família, mantendo então uma fonte de renda.

A carne do lilio foi recentemente degustada por nutricionista do município e poderá ser incrementada na merenda escolar, surgindo então, outra forma de inserir o produto na economia local gerando mais fonte de renda. Assim sendo, essa atividade necessita, de uma atenção maior pelo poder público para que seja desenvolvida dentro de padrões sanitários e ambientais adequados para que se possa incrementar a economia local de forma organizada.

Quanto aos impactos sobre a saúde dos pescadores verificou-se que, o processo de captura e de beneficiamento do lilio, ao ser realizado de forma artesanal, com o uso de equipamentos e instrumentos rudimentares feitos pelos próprios pescadores, consiste em uma rotina bastante cansativa desenvolvida ao longo do dia. Além disso, em todo o processo, os pescadores não utilizam nenhum tipo de equipamento de proteção individual (EPI), ficando totalmente expostos ao risco de acidentes que vai desde a utilização de embarcações para fazer a travessia, a extração do molusco, a retirada da lenha, o risco de acidente com animais peçonhentos, a exposição à fumaça e ao fogo durante o pré-cozimento, os riscos ergonômicos com o transporte do produto, que é feito pelos próprios pescadores, além do risco de lesão por esforço repetitivo e doenças osteoarticulares relacionada ao trabalho (ler/dort) no processo de retirada da carne que é feita de forma manual.

\subsection{Impactos ambientais a partir do descarte inadequado do resíduo}

Os impactos ambientais associados a pesca artesanal do lilio se dá a partir do descarte das conchas, a céu aberto no próprio local, em quintais próximos as residências ou em terrenos baldios. Em todos os locais visitados constatou-se a agressão ao meio ambiente provocada pela a atividade específica do beneficiamento desse molusco.

O problema de descarte inadequado na localidade de Patané é antiga. Existiam até o ano de 2014 oito pontos de chegada de pescadores conhecidos como pequenos portos. No ano de 2014 o Instituto de Desenvolvimento Sustentável e Meio Ambiente do Rio Grande do Norte (Idema) realizou fiscalização nessas localidades e proibiu a atividade em metade dos portos que se encontrava em situação mais crítica, degradando o manguezal em virtude da atividade do beneficiamento, restringindo a pesca em apenas quatro portos: Porto de Israel, o Porto das Pedras, o Porto de Camuci e o Porto de Zé Galvão.

O órgão ambiental estadual determinou a remoção das conchas acumuladas nos locais, porém essa remoção só foi realizada no porto de Zé Galvão, devido à dificuldade de acesso de caminhões e máquinas nos demais portos, persistindo, portanto, o acúmulo de resíduos no solo, como pode ser visto na Figura 02, nos demais pontos de descarte. 

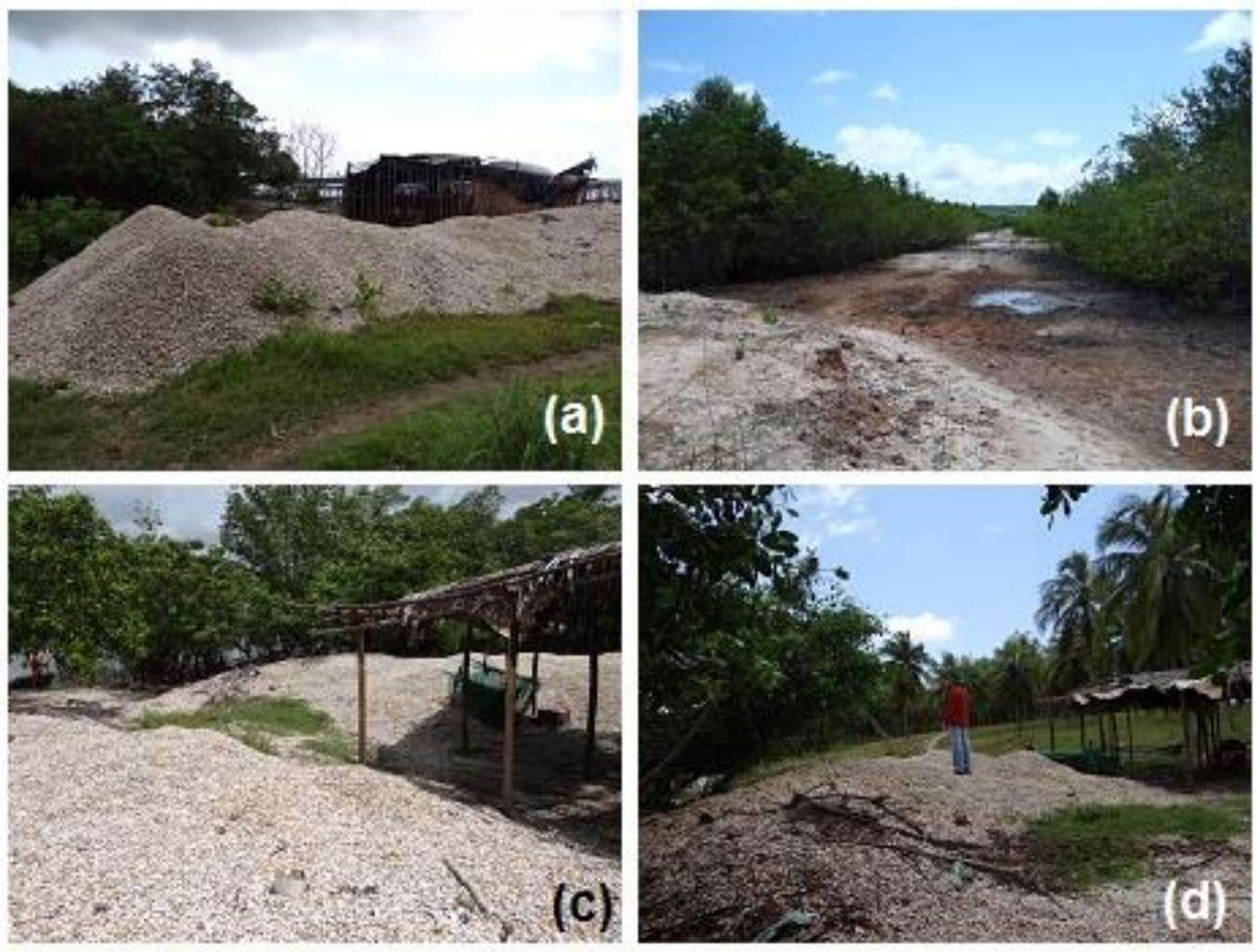

Figura 02. Locais de descarte de conchas (a) Porto de Camuci (b) Porto de Zé Galvão (c) Porto da Pedra (d) Porto de Israel

Fotos: Os autores (2015)

A Secretaria de Meio Ambiente do município removeu as conchas acumuladas no Porto de Zé Galvão que se adentrava ao manguezal como pode ser visto na Figura 2(b), com intuito de amenizar o dano ao meio ambiente, até que seja encontrada uma solução definitiva para o problema, mesmo sabendo que essa limpeza é paliativa e que os pescadores voltarão a descartar as conchas novamente no local. As conchas foram depositadas em um terreno baldio de propriedade da prefeitura e misturadas ao solo para servir como aterramento ou regularização do terreno, tendo envolvido um volume de aproximadamente 50 caminhões caçambas nessa operação $\left(300 \mathrm{~m}^{3}\right)$.

De uma maneira geral a fiscalização do órgão ambiental estadual foi benéfica, porém ainda ineficaz, pois enquanto não se encontre soluções para esse problema essa situação vai perdurar tendo em vista as questões sociais associadas a essa atividade. De acordo com os fiscais do Idema, os outros locais de beneficiamento do molusco passarão pelas mesmas intervenções, ficando os pescadores proibidos de exercerem a pesca e o beneficiamento no entorno dos portos, caso persistam os problemas ambientais, podendo essa ação trazer grave crise financeira e social para a comunidade.

O resíduo proveniente do beneficiamento que é descartado no próprio local, às margens do estuário da Lagoa de Guaraíras, além de causar a poluição visual da área com os grandes volumes de resíduos amontoados nos pontos, impacta diretamente na regeneração do manguezal tendo em vista que na medida em que os resíduos avançam sobre o mangue, sufoca o brotamento de novas mudas de manguezal comprometendo a regeneração de áreas degradas pela a atividade. Quando o resíduo é depositado em quintais ou terrenos baldios gera incômodos sanitários de odor e atração de vetores, conforme também foi diagnosticado por Rocha (2009) e Rego Neto e Batista 
(2014) em estudos realizados com pescadores na reserva de Ponta do Tubarão, no município de Macau/RN.

Outro impacto ambiental gerado pelo descarte das conchas a céu aberto é o assoreamento do mangue pois quando o resíduo é depositado muito próximo à margem, na medida em que aumenta o nível da maré, esses resíduos são deslocados para dentro do estuário da Lagoa de Guaraíras, comprometendo também, pequenos canais que deságuam no estuário. É importante frisar que esse resíduo que é levado para o fundo do estuário pode comprometer algumas comunidades marinhas, além de assorear a lagoa.

Também foi constatado a supressão vegetal de manguezais e mata ciliar para utilização como combustível para realizar o pré-cozimento do molusco e consequentemente a retirada da carne. Esse recurso é bastante utilizado nesse processo, devido não gerar nenhum custo para os pescadores, além da facilidade de se encontrar a matéria prima no entorno do mangue ou na mata próxima aos locais de extração ou de beneficiamento do molusco, conforme também foi verificado por Rocha (2009). Outros tipos de madeiras foram evidenciados em alguns locais de beneficiamento tais como galhos provenientes de podas de árvores frutíferas, o que pode ser menos agressivo ao meio ambiente pois substitui a retirada de lenha do entorno do manguezal e ao mesmo tempo pode dar destino à poda da área urbana.

De um modo geral o manguezal vem sendo impactado constantemente sem nenhuma ação que possa amenizar os danos cometidos ao meio ambiente. Segundo a resolução CONAMA $n^{\circ}$. 369/2006, "as áreas de mangue não devem sofrer qualquer tipo de intervenção em sua vegetação" (BRASIL, 2006). Verifica-se portanto, que esse importante ecossistema vem sofrendo agressões que precisam ser cessadas, ao mesmo tempo em que a atividade precisa ser tratada de uma forma profissional para evitar esses danos. Contrariando a determinação da legislação, diversos pescadores cometem crimes ambientais, por falta de conhecimento e por falta de alternativa viável para o desenvolvimento dessa atividade.

\subsection{Alternativas para o aproveitamento do resíduo}

Segundo Chierighini et al. (2011) as conchas do molusco bivalves, tem como principal constituinte o carbonato de cálcio $\left(\mathrm{CaCO}_{3}\right)$. Esse material pode ser utilizado na agricultura, indústria, artesanato dentre outras alternativas. Segundo Boicko et al. (2007) o carbonato de cálcio pode ser usado em diversos processos produtivos tais como construção de estradas, pasta de papel, mármore compacto para pavimentos e revestimento, adubos e pesticidas, rações, indústria da cerâmica, tijolos, tintas, espumas de polietileno, talcos, vidros, cimentos, vernizes e borrachas, impermeabilizantes de lagoas, correção de solos, medicamentos, carga de polímeros, entre outros.

Os estudos para reaproveitamento desse resíduo no Brasil ainda são incipientes para a dimensão do nosso litoral e o elevado índice de pescadores envolvidos na pesca artesanal, assim como em projetos de malacocultura ${ }^{1}$ e maricultura ${ }^{2}$. O resíduo gerado está sendo totalmente desperdiçado por falta de conhecimento do real potencial desse material que poderia está incluído na composição de diversos produtos como citado por Chierighini et al. (2011), Boicko et al. (2004), Batista et al. (2008), Lo Monaco et al. (2012), Costa et al. (2012) e Tenório et al. (2014).

\footnotetext{
${ }^{1}$ Criação ou cultivo de moluscos para consumo humano.

${ }^{2}$ Criação ou cultivo especifico de organismo marinhos.
} 
Conforme foi constatado nas visitas in loco, há um grande acúmulo de material descartado a céu aberto, totalmente desperdiçado sem nenhuma perspectiva de reaproveitamento. Esses resíduos poderiam gerar uma segunda fonte de renda para os pescadores com o beneficiamento das conchas ou a venda direta desse resíduo que serviria de matéria prima para outro produto, gerando assim uma cadeia produtiva a partir das conchas de lilio.

De acordo com Lo Monaco et al. (2012) umas das possíveis alternativas para viabilizar o reaproveitamento desse resíduo é sua utilização como corretivo de acidez do solo. Diante dessa alternativa, o impacto positivo seria na redução de extração de rochas de calcário, tendo em vista que o calcário é bastante utilizado na agricultura para correção dos solos como comentado por Costa et al. (2012).

A indústria da construção civil também poderia se inserir na cadeia de utilização desse resíduo processado, tais como em uso em contra pisos de casas, conforme foi citado por moradores da região, que já usaram o resíduo como essa alternativa. Segundo Rego Neto e Batista (2014), essa alternativa possibilitaria a diminuição da utilização da areia em construções, pois o resíduo triturado, que é constituído de cálcio, apresenta maior resistência dos materiais e tem poder de absorção de menos água podendo contribuir na diminuição dos custos na construção. Existem pesquisas em algumas regiões brasileiras com a reutilização do resíduo na confecção de blocos e tijolos cerâmicos conforme foi mencionado por Batista et al. (2008) e Tenório et al. (2014). As conchas também poderiam ter outra finalidade no município de Arez/RN, tais como a reutilização como aterro em regularização das estradas vicinais de acesso a zona rural, necessitando de estudos para orientações técnicas de como utilizar corretamente.

O zooartesanato ${ }^{3}$ é também uma das alternativas de reutilização para esse resíduo, gerando empregos para as próprias famílias dos pescadores. Essa atividade é predominantemente manual para a produção de bens, sendo geralmente exercida em ambiente doméstico, em pequenas oficinas ou centros associativos, conforme cita Alves et al. (2010). A principal matéria prima nessa atividade são as conchas dos moluscos que são coletados ou comprados diretamente de pescadores, evitando, assim, o descarte inadequado durante a etapa de beneficiamento. Também existe a possibilidade da venda do resíduo para que outras pessoas confeccionem os artesanatos gerando lucros a partir da venda do resíduo, além de gerar uma cadeia produtiva a partir da captura do molusco até a destinação final do resíduo de forma adequada. Segundo Alves et al. (2006) a A. brasiliana é a espécie mais encontrada na composição do zooartesanato exposto nos estabelecimentos comerciais de Recife e também alguns moluscos são pescados por encomendas ou casualmente e separados para a confecção de objetos decorativos.

\section{CONCLUSÕES}

A captura do molusco A. brasiliana na comunidade de Patané, distrito de Arez/RN é uma atividade que envolve diversas famílias de pescadores que sobrevivem exclusivamente da pesca artesanal ou mesmo como forma de complementar a renda da família, porém essa atividade tem causado grandes impactos ao meio ambiente decorrentes do descarte inadequado de resíduos no solo. Além disso, há impactos sociais relativos à captura e beneficiamento do produto devido essa

\footnotetext{
${ }^{3}$ É qualquer forma de artesanato que utiliza animais ou partes destes no processo de confecção de peças.
} 
atividade ser realizada com poucos recursos tecnológicos envolvendo grande esforço físico e infraestrutura inadequada à atividade.

O descarte inadequado dos resíduos do beneficiamento do molusco lilio é decorrente da ausência de gestão da atividade, sobretudo devido à falta de capacitação dos pescadores, a precariedade nas estruturas físicas de beneficiamento e dificuldade de acesso aos locais de beneficiamento, a ausência de estudos sobre alternativas locais para reuso ou reciclagem em outros processos produtivos, e a estrutura deficiente do órgão ambiental local para solucionar definitivamente o problema. O grande desafio é desenvolver alternativas economicamente e tecnicamente viáveis para o beneficiamento das conchas que se amontoam em grandes volumes no próprio local de processamento, às margens do manguezal ou em quintais e terrenos baldios.

Possíveis alternativas para a situação estudada seria reunir os pescadores do lilio para formalização de uma associação ou cooperativa, valorizando o trabalho dos envolvidos, agregando valor ao produto e melhorando as condições de produção. Com a formalização de uma associação os mesmos teriam maior poder de comercialização da produção, eliminando os atravessadores, o que possibilitaria a obtenção de um melhor preço para o produto comercializado. Em função dessa associação os mesmos teriam mais oportunidades de ter acesso a recursos públicos e também da iniciativa privada, além de maior facilidade para aquisição de máquinas e equipamentos, melhorando dessa forma o processo de beneficiamento.

A construção de galpões de beneficiamento com toda uma estrutura adequada para execução das atividades é outro ponto essencial, bem como investir numa logística para transportar a produção dos portos até os galpões de beneficiamento, além de capacitação dos atores envolvidos na atividade. A construção desses galpões também resolveria o problema do descarte inadequado em vários pontos, passando a centralizar em pontos específicos que não venha a prejudicar o manguezal.

Com relação às alternativas para reutilização desse resíduo se faz necessário pesquisar dentre as diversas já utilizadas em outras localidades e mencionadas na literatura, qual seria a que melhor se adequa à realidade socioeconômica da comunidade.

A comercialização das conchas in natura ou beneficiadas pode gerar uma segunda fonte de renda para os pescadores possibilitando a participação de mais pessoas nessa cadeia produtiva. Qualquer alternativa que venha ser adotada para este fim deve ser viável economicamente como também ambientalmente sustentável. Para que tudo ocorra de forma correta é necessário o engajamento de todos os atores envolvidos tais como: pescadores, prefeitura, órgão ambientais fiscalizadores, promotoria do município, ONG's e iniciativa privada, todos voltados para um manejo de forma sustentável e uma melhoria nas condições sociais da comunidade.

\section{REFERÊNCIAS BIBLIOGRÁFICAS}

1. Alves, M. S.; Silva, M. A.; Júnior, M. M.; Paranaguá, M. N.; Pinto, S. L. Zooartesanato comercializado em Recife, Pernambuco, Brasil. Revista Brasileira de Zoociências. v. 8, n. 2, p. 99-109, dezembro 2006.

2. Alves, M. S.; Silva, M. A.; Pinto S. L. Perfil sócio-econômico dos atores envolvidos na produção e comercialização de zooartesanato em Recife, Pernambuco - Brasil Revista Nordestina de Zoologia - Recife V. 4 N. 1 -p. 97-104 - 2009/2010 
3. BRASIL. Resolução CONAMA no 369, de 23 de março de 2006. Dispõe sobre os casos excepcionais, de utilidade pública, interesse social ou baixo impacto ambiental, que possibilitam a intervenção ou supressão de vegetação em Área de Preservação PermanenteAPP. Diário Oficial da República Federativa do Brasil, Brasília, s. 1, p. 150 - 151- correlações: 29 de março, 2006.

4. Boicko, A.L.; Hotza, D.; Sant'anna, F.S.P. Utilização das conchas da ostra Crassostrea gigas como carga para produtos de policloreto de vinila (pvc). Anais IV Simpósio Internacional de Qualidade Ambiental, v.1, p. 1- 8. Porto Alegre, 2004.

5. Batista, B. B., Silva, H. T.; Dos Santos, M. V.; Ortiz, P. E. Reaproveitamento de Resíduos da Construção Civil e de Conchas de Ostras e Mariscos. 2008. Disponível em:<http://www.blocoverde.com.br/arquivos/artigosfm.pdf. Acesso em: 15 de agosto de 2015.

6. Chieringhini, D.; Bridi, R.; da Rocha, A. A.; Lapa, K. R. Possibilidades do Uso das Conchas de Moluscos. São Paulo, Brasil, p. 5, 2011.

7. Costa, A. R. S.; Oliveira, B. M. C.; Araújo, G. V. R.; Silva, T. E. P.; El-Deir, S. G. Viabilidade do uso de conchas de mariscos como corretivos de solos. III Congresso Brasileiro de Gestão Ambiental, Goiânia/GO- 19 a 22/11/2012.

8. Dias, T. L. P.; Rosa, R. S.; Damasceno, L. C. P. Aspectos socioeconômicos, percepção ambiental e perspectivas das mulheres marisqueiras da reserva de Desenvolvimento Sustentável Ponta do Tubarão (Rio Grande do Norte, Brasil). Gaia Scientia, v. 1, n. 1, p. 25-35, 2007.

9. Gil, A. C. Como elaborar projetos de pesquisa. 4. ed. São Paulo: Atlas, 2008.

10. IBGE - Instituto Brasileiro de Geografia e Estatística. Censo Demográfico. Informações Estatísticas, cidades, AREZ/RN, Informações completas. Rio de Janeiro, 2010.

11. IDEMA. Instituto de Desenvolvimento Sustentável e Meio Ambiente do Rio Grande do Norte. Unidade de Conservação. Área de proteção ambiental Bonfim-Guaraíras. Natal, RN. 2014.

12. Lima, H. C., Barbosa, J. M., Correia. D. S. Extração de Mariscos por Moradores da Comunidade de Beira-Mar 2, Iguarassu PE. In: VII Jornada e Ensino, Pesquisa e Extensão, 2007, Manguezais p. 108-109. Recife, Editora da UFPE, 2007.

13. Lo Monaco, P. A. V.; Matos, A. T.; Junior, V. E.; Ribeiro, I. C. A.; Teixeira, D. L. Utilização do farelo de conchas de vôngole na adsorção de fósforo e como corretivo da acidez do solo. Artigos científicos engenharia de água e solo. Eng. Agríc. Vol.32 no. 5 Jaboticabal Sept./Oct.2012.

14. Nishida, A. K. Catadores de moluscos do litoral Paraibano. Estratégias de subsistência e formas de percepção da natureza. São Carlos, SP, 2000, 143 p. (Tese de Doutorado) - UFSCar, Pós-graduação em Ecologia e Recursos Naturais, do Centro de Ciências Biológicas e da Saúde.

15. Pereira Filho, O.; Alves, J.R.P. Conhecendo o manguezal. Apostila técnica, Grupo Mundo da Lama, RJ. 4a ed. p. 10, 1999.

16. Rego Neto, L. G.; Batista, M. S. S. (2014) Os impactos ambientais da pesca artesanal: Perspectivas de educação ambiental com mulheres marisqueiras. V Semana de Estudos, Teorias e Práticas Educativas. UERN, Pau dos Ferros/RN. Disponível em: http://www.editorarealize.com.br/revistas/setepe/trabalhos/Modalidade_1datahora_22_09 _2014_11_45_51_idinscrito_7_60ceaf95298f372cc11efc95b8baadbb.pdf. Acesso em: 05 de 
ago 2015.

17. Rocha, L. M. Áreas Marinhas Protegidas e o Manejo de Pesca: A (In) Visibilidade dos Búzios (Anomalocardia brasiliana - Veneridade) (Gmelin, 1791) e das Marisqueira na RDS Estadual Ponta do Tubarão (RN). In: Congresso Brasileiro de Unidades de Conservação, 6, 2009. Curitiba. Anais. Curitiba, Fundação o Boticário de Proteção à Natureza, 2009.

18. Silva, D. Resíduo sólido da malacocultura: caracterização e potencialidade de utilização de conchas de ostras e mexilhão. Dissertação de Mestrado em Engenharia Ambiental, Universidade Federal de Santa Catarina - UFSC. Florianópolis, 2007.

19. Tenório, H. C. L.; Motta, P. M. S.; Gonçalves, L. B.; Marinho, A. A. Reaproveitamento de conchas de mariscos e resíduos da construção civil em Alagoas. Ciências exatas e tecnológicas. Maceió. v. 1, n.1, p. 61-71, maio 2014. periodicos.set.edu.br 